\title{
HUBUNGAN BELAJAR BERDASAR REGULASI DIRI TERHADAP PERILAKU MENYONTEK MAHASISWA
}

\author{
Raihanatu Binqalbi Ruzain ${ }^{1}$, Yulia Hastuti ${ }^{2}$, Aldita Permata Putri ${ }^{3}$ \\ Universitas Islam Riau \\ Raihanatu.binqolbi@psy.uir.ac.id
}

\begin{abstract}
ABSTRAK
Tingginya persentase perilaku meyontek yag dilakukan oleh mahasiswa di kampus (50$70 \%$ ). Belajar berdasar regulasi diri sangat diperlukan untuk mencegah perilaku menyontek di dunia pendidikan. Tujuan penelitian ini untuk mengetahui hubungan antara belajar berdasar regulasi diri dengan perilaku menyontek mahasiswa di Pekanbaru. Penelitian ini bersifat kuantitatif dengan korelasi Product Moment. Subjek penelitian ini adalah mahasiswa Universitas Islam Riau yang berjumlah 150 orang dipilih secara acak dengan teknik cluster sampling. Belajar berdasarkan regulasi diri sebagai variable bebas dan perilaku menyontek sebagai variable terikat. Skala belajar berdasarkan regulasi diadaptasi dari skala Jusar dan kala perilaku menyonyek diadaptasi dari Priaswandy. Dipenelitian terdapat hubungan negatif antara belajar berdasar regulasi diri terhadap perilaku menyontek. Hubungan negatif tersebut menunjukkan bahwa semakin tinggi perilaku menyontek, maka semakin rendah belajar berdasar regulasi dirinya. Begitu juga sebaliknya, semakin rendah perilaku menyontek, maka semakin tinggi belajar berdasar regulasi dirinya. Mahasiswa disarankan untuk bisa membuat skala prioritas dalam aktivitas sehari-hari, skala prioritas mengerjakan tugas perkuliahan, manajemen waktu dan tidak menunda-nunda mengerjakan tugas perkuliahan.
\end{abstract}

Kata Kunci: Belajar, Regulasi diri, Perilaku menyontek

\section{PENDAHULUAN}

Perilaku menyontek atau melakukan kecurangan dilakukan hampir 50-75 persen siswa dan mahasiswa (Baird 1980; Stevens and Stevens 1987). Perilaku menyontek merupakan tindakan menyimpang dan atau curang yang melanggar norma social dilakukan seseorang untuk mendapatkan keuntungan (Albrecht, 2006; Manik,2013).

Islam juga melarang manusia untuk berbuat curang dan berbohong, Nabi Shallallahu'Alaihi Wasallam bersabda;

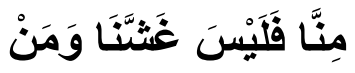

Artinya: "Barang siapa menipu kami, maka ia tidak termasuk golongan kami." (HR. Muslim)

Di dunia pendidikan dalam beberapa tahun terakhir, perilaku menyontek menjadi semakin sering terjadi (McCabe \&Trevino,1997), mulai tingkat pendidikan SD, SMP, dan SMA dan terbawa sampai ke perguruan tinggi( Murdock, Hale \& Weber, 2001; 
Davis, Grover, Becker, \& McGregor,1992). Pendidikan yang hanya berfokus pada pencapaian nilai akademis serta mengabaikan proses pembelajaran dan pengusaan materi akan mengakibatkan penurunan peran serta aktif kognitif dan pola adaptasi motivasi (Elias, 2009).

Kampus sebagai salah satu satu institusi pendidikan memainkan peran penting dalam kelahiran generasi intelektual yang baik. Peran aktif lembaga pendidikan tidak hanya berupa transfer ilmu pengetahuan tetapi juga berperan aktif dalam membentuk karakter dan nilai-nilai integritas mahasiswa sebagai persiapan memasuki tempat kerja atau dunia bisnis. Penelitian terkait dengan perilaku menyontek, ketidakjujuran akademis dan curang yang dilakukan oleh mahasiswa di masa pendidikan akan terkait dengan perilaku ketidakjujuran di masa kerja serta perilaku menyimpang dan kriminal lainnya (Alschuler, A. S., \& Blimling, G. S, 1995; Sims, 1993).

Perilaku menyontek yang dilakukan oleh mahasiswa dipengaruhi oleh faktor-faktor individu, lingkungan sebaya dan perspektif sosial kognitif, faktor perspektif sosial kognitif penelitian ini adalah regulasi diri (Bandura, Caprara, Barbaranelli, Pastorelli \& Regalia, 2001).

Belajar berdasarkan regulasi diri merupakan kemampuan aktif seseorang untuk mengatur dirinya dalam aspek metakognisi, motivasi, dan perilaku aktif. Belajar berdasarkan regulasi diri akan berdampak terhadap perfomansi seseorang dalam pencapaian prestasi atau kinerjanya (Zimmerman, 2005). Belajar berdasarkan regulasi diri juga mebuat seseroang kembali berada pada aturan standar yang ada sehingga hal ini mengontrol dirinya tidak melakukan perbuatan yang melenceng (Baumeister, 1996)

Belajar berdasarkan regulasi diri adalah suatu proses yang membantu mahasiswa untuk mengelola pikiran, perilaku, dan emosi mereka agar berhasil menavigasi pengalaman belajar mereka. Proses ini bertujuan agar mahasiswa mendapatkan keterampilan yang baik sehingga terbentuk performans yang baik. Belajar berdasarkan regulasi diri meliputi pemikiran dan perencanaan, pemantauan kinerja, dan refleksi pada kinerja (Pintrich \& Zusho, 2002; Zimmerman, 2000).

diri,

Didalam Q.S Al-hasyr ayat 18, Allah telah menjelaskan tentang pentingnya Regulasi

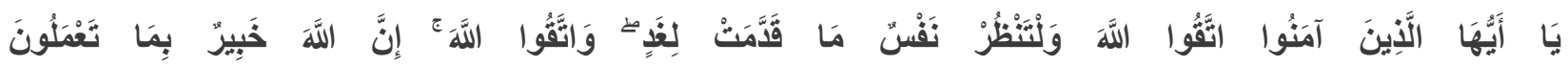

Artinya: "Wahai orang orang yang beriman, Bertakwalah kepada Allah dan hendaklah setiap orang memperhatikan apa yang telah diperbuatnya untuk hari esok (akhirat), dan bertakwalah kepada Allah. Sungguh Allah Maha Teliti terhadap apa yang kamu kerjakan". (Q.S Al Hasyr: 18)

. Dalam Q.S Al-mujadalah ayat 11, Allah SWT menyatakan bahwa orang orang yang berilmu dan beriman akan ditinggikan derajatnya.

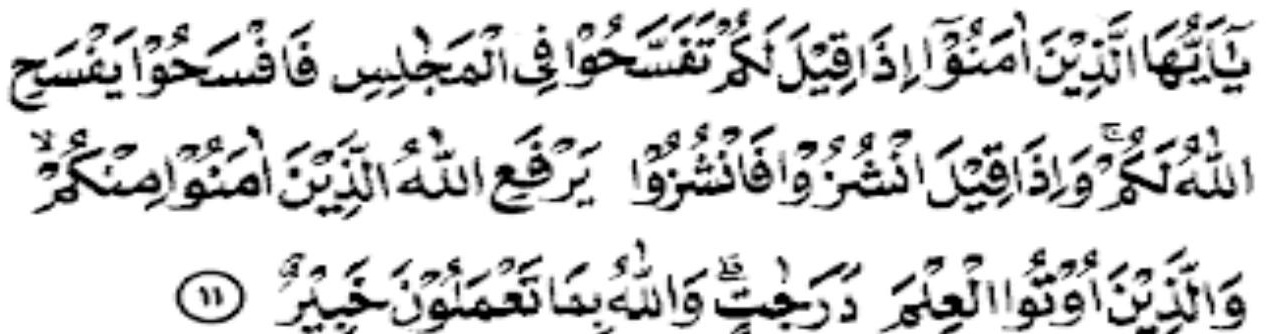


Artinya "Wahai orang-orang yang beriman, apabila dikatakan kepadamu,"berilah kelapangan didalam majelis-majelis", makalapangkanlah, niscaya Allah akan memberi kelapangan untukmudan apabiladikatakan, "berdirilah kamu", maka berdirilah,niscaya Allah akanmengangkat (derajat) orang orang yang beriman diantaramudan orang orang yang diberi ilmu

Dan dalam Q.S Al- insyirah ayat 5-8, Allah SWT memerintahkan manusia untuk bersungguh- sungguh dalam bekerja dan beraktifitas.

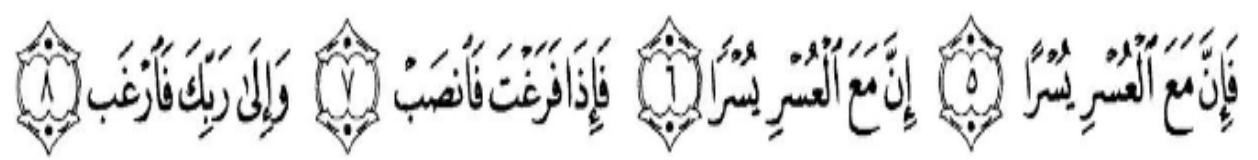

Artinya : "maka sesungguhnya bersama kesulitan ada kemudahan"(5) "sesungguhnya bersama kesulitan ada kemudahan"(6) "maka apabila engkau telah selesai (dari sesuatu urusan) tetaplah bekerja keras (untuk urusan yang lain)"(7)"dan hanya kepada Tuhanmulah engkau berharap"(8)

Belajar berdasarkan regulasi diri yang buruk menimbulkan prestasi yang rendah berupa seseorang kurang mampu bertahan terhadap kegagalan ,kurang mampu mengattur kinerja yang efektif, kurang mampu menentukan tujuan serta pencapainnya dan kurang mampu mempertahankan upaya maksimal dalam jangka waktu tertentu(( Baumeister, 1996)

\section{METODOLOGI}

Penelitian ini bersifat kuantitatif dengan korelasi Product Moment obsevasional. Subjek penelitian ini adalah mahasiswa Universitas Islam Riau yang berjumlah 150 orang. Terdiri dari 5 fakultas, yaitu Fakultas Teknik Sipil, Fakultas Teknik Informatika, Fakultas Psikologi Psikologi, Fakultas Pertanian Prodi Agribisnis dan Fisipol Prodi Ilmu Pemerintahan. Masing-masing fakultas terdiri dari 30 orang yang akan dipilih secara acak dengan teknik cluster sampling. Belajar berdasarkan regulasi diri sebagai variable bebas dan perilaku menyontek sebagai variable terikat.

Belajar berdasarkan regulasi diri didefiniskan sebagai suatu proses dimana seseorang melakukan strategi untuk meregulasi kognisi, metakognisi, dan motivasi. Skala belajar berdasarkan regulasi diadaptasi dari skala Jusar. Dengan bentuk skala Likert 
dengan empat respon jawaban, yaitu sangat setuju (SS), setuju (S), tidak setuju (TS) dan sangat tidak setuju (STS).

Perilaku menyontek didefinisikan sebagai tindakan menyimpang dan atau curang yang melanggar norma sosial dilakukan seseorang untuk mendapatkan keuntungan. Skala perilaku menyonyek diadaptasi dari Priaswandy. Dengan skala Likert dengan empat respon jawaban, yaitu sangat setuju (SS), setuju (S), tidak setuju (TS) dan sangat tidak setuju (STS).

Signifikansi hubungan diketahui dengan menggunakan product moment (korelasi Pearson). Analisis ini untuk mengetahui hubungan antara belajar berdasarkan regulasi diri dengan perilaku menyontek

\section{HASIL PENELITIAN}

\section{DESKRIPSI DATA PENELITIAN}

Penelitian dilaksanakan pada hari Senin tanggal 28 Maret 2019 dengan jumlah sampel 150 orang mahasiswa Universitas Islam Riau . Penyebaran dan hasil pengisian angket dilakukan dengan google forms yang dibagikan melalui elektronik WhatsApp, facebook dan Instagram untuk mempermudah subjek dalam mengisi kuisioner. Subjek sebelumnya diberi pengarahan terlebih dahulu mengenai tata cara pengisian. Subjek diberikan sebuah link yang berisi dua skala, yaitu skala perilaku menyontek sebanyak 16 aitem dan skala belajar berdasar regulasi diri sebanyak 27 aitem.

Hasil penelitian mengenai hubungan belajar berdasar regulasi terhadap perilaku menyontek mahasiswa dengan jumlah sampel 150 orang. Setelah dilakukan skoring dan diolah dengan bantuan program komputer SPSS 17,0 for windows maka diperoleh gambaran seperti yang disajikan dalam table berikut

Tabel 1 Deskripsi Data Penelitian

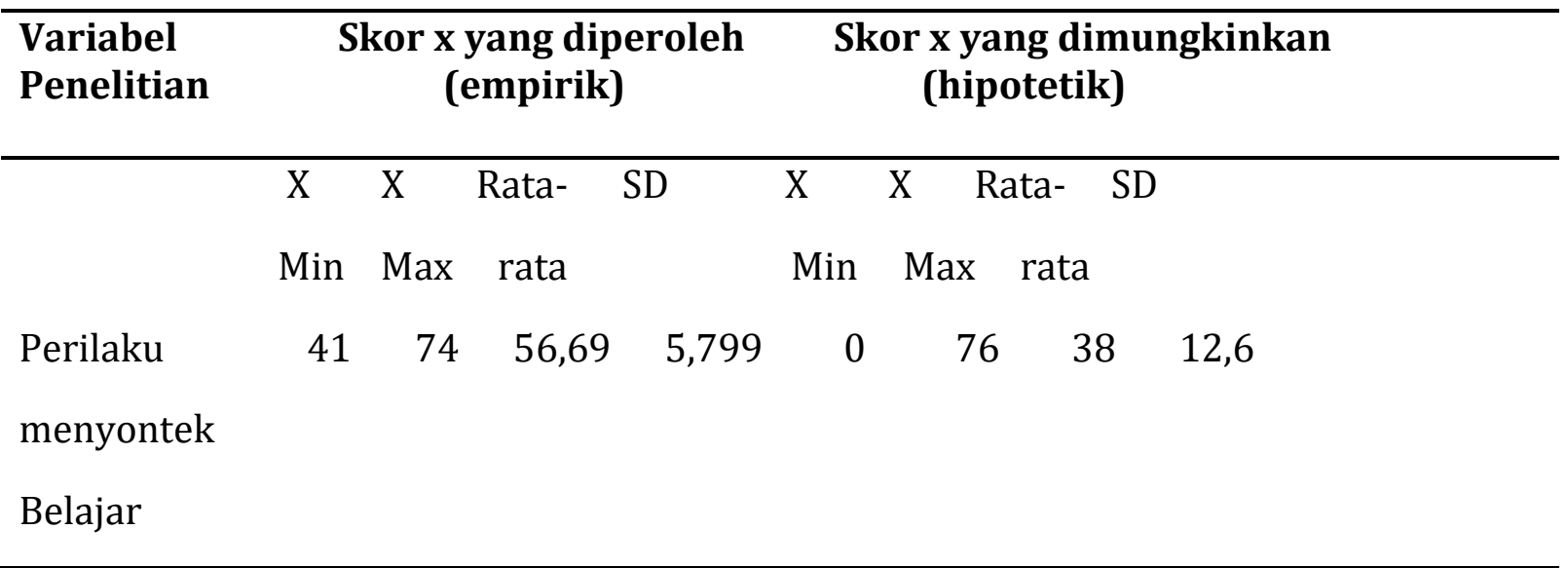




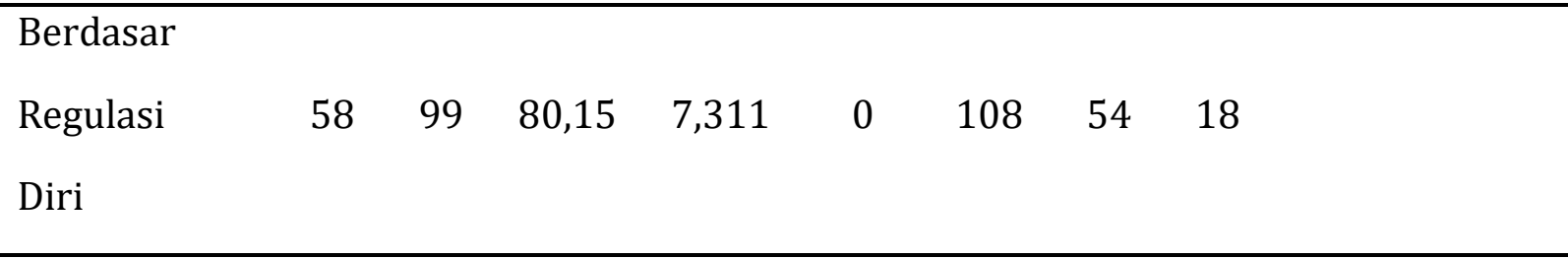

Tabel 1 diatas secara umum menggambarkan bahwa perilaku menyontek pada mahasiswa bervariasi, terlihat dari rentang skor yang diperoleh bergerak dari 74 sampai 41. Skor belajar berdasar regulasi diri juga bervariasi bergerak antara 99 sampai 58 . Tabel 1 diatas juga memberikan perbandingan antara skor yang dimungkinkan diperoleh subjek (hipotetik) dengan skor yang diperoleh setelah dilakukan penelitian.

Berdasarkan deskripsi data hipotetik diatas, dapat dilihat bahwa nilai rata-rata untuk perilaku menyontek dan belajar berdasar regulasi diri pada mahasiswa memiliki rentang 54 dan 38 dengan standar defiasi 18 dan 12,6. Diketahui bahwa kedua variabel memiliki skor rata-rata empirik yang lebih tinggi dari pada skor rata-rata hipotetik. Ada lima kategori yang akan penulis gunakan dalam penelitian ini yaitu, sangat setuju (SS), Setuju (S), tidak setuju (TS), dan sangat tidak setuju (STS) yang ditentukan dengan norma berikut :

Tabel 2 Rumus Kategorisasi

\begin{tabular}{lc}
\hline Kategori & Rumus \\
\hline Sangat tinggi & $\mathrm{X} \geq \mathrm{M}+1,5 \mathrm{SD}$ \\
Tinggi & $\mathrm{M} \leq \mathrm{X}<\mathrm{M}+1,5 \mathrm{SD}$ \\
Rendah & $\mathrm{M}-1,5 \mathrm{SD} \leq \mathrm{X}<\mathrm{M}$ \\
Sangat Rendah & $\mathrm{M}-1,5 \mathrm{SD} \geq \mathrm{X}$ \\
\hline
\end{tabular}

\section{Keterangan : \\ $M$ : Rata-rata \\ SD : Standar Deviasi}

Berdasarkan tabel 1 dapat diketahui bahwa variabel perilaku menyontek memiliki ratarata hipotetik sebesar 38 sedangkan empirik sebesar 56,69 dan standar deviasi hipotetik sebesar 12,6 sedangkan standar deviasi empirik sebesar 5,799. Dengan norma diatas kita dapat menemukan kategori (kriteria) penilaiannya. Kriteria veriabel perilaku menyontek dapat dilihat pada tabel 3 sebagai berikut: 
Tabel 3 Kategorisasi Variabel Perilaku Menyontek

\begin{tabular}{ccccccc}
\hline $\begin{array}{c}\text { Rentang } \\
\text { Nilai } \\
\text { (Empirik) }\end{array}$ & Frekuensi & $\%$ & Kategori & $\begin{array}{c}\text { Rentang } \\
\text { Nilai } \\
\text { (Hipotetik) }\end{array}$ & Frekuensi & $\%$ \\
\hline $\mathrm{X} \geq 65,38$ & 11 & $7,3 \%$ & $\begin{array}{c}\text { Sangat } \\
\text { Tinggi }\end{array}$ & $\mathrm{X} \geq 56,9$ & 73 & $48,7 \%$ \\
$\begin{array}{c}56,69 \leq \mathrm{X}< \\
65,38\end{array}$ & 62 & $41,3 \%$ & Tinggi & $38 \leq \mathrm{X}<56,9$ & 77 & $51,3 \%$ \\
$\begin{array}{c}47,9 \mathrm{X}< \\
56,69\end{array}$ & 70 & $46,7 \%$ & Rendah & $3 \mathrm{I}, 7 \leq \mathrm{X}<38$ & 0 & $0 \%$ \\
$\mathrm{X} \leq 47,9$ & 7 & $4,7 \%$ & $\begin{array}{c}\text { Sangat } \\
\text { Rendah }\end{array}$ & $\mathrm{X} \leq 31,7$ & 0 & $0 \%$ \\
\hline Total & 150 & $100 \%$ & & Total & 150 & $100 \%$ \\
\hline
\end{tabular}

Berdasarkan table 3 diatas, dapat diketahui bahwa sebagian besar subjek jika dilihat dari data hipotetik berada pada kategori sangat tinggi yaitu sebanyak 73 orang atau 48,7\%, kategori tinggi 77 orang atau 51,3\%, dan tidak ada atau $0 \%$ di dalam kategori rendah, sangat rendah. Jika dilihat dari data empirik sebagian besar subjek memiliki perilaku menyontek dengan kategori rendah yaitu 70 orang atau 46,7\%, 62 orang atau $41,3 \%$ berada pada kategori tinggi, 11 orang atau 7,3\% berada pada kategori sangat tinggi, dan 7 orang atau $4,7 \%$ berada dalam kategori sangat rendah. Dalam penelitian ini penulis menggunakan kategorisasi berdasarkan data empirik.

Pada tabel 1 dapat diketahui bahwa variabel belajar berdasar regulasi diri pada mahasiswa memiliki rata-rata empirik sebesar 80,15 sedangkan rata-rata hipotetik sebesar 54 dan standar deviasi empirik 7,311 sedangkan standar deviasi hipotetik sebesar 18. Sesuai dengan norma maka kita dapat menentukan kategori (kriteria) penilaiannya. Kriteria variabel belajar berdasar regulasi diri dapat dilihat pada tabel 4 sebagai berikut :

Tabel 4. Kategorisasi Belajar Berdasar Regulasi Diri

\begin{tabular}{ccccccc}
\hline $\begin{array}{c}\text { Rentang } \\
\text { Nilai } \\
\text { (Empirik) }\end{array}$ & Frekuensi & $\%$ & Kategori & $\begin{array}{c}\text { Rentang } \\
\text { Nilai } \\
\text { (Hipotetik) }\end{array}$ & Frekuensi & $\%$ \\
\hline $\mathrm{X} \geq 91,11$ & 7 & $4,7 \%$ & $\begin{array}{c}\text { Sangat } \\
\text { Tinggi }\end{array}$ & $\mathrm{X} \geq 81$ & 63 & $42 \%$ \\
$\begin{array}{c}80,15 \leq \mathrm{X}< \\
91,11\end{array}$ & 92 & $61,3 \%$ & Tinggi & $54 \leq \mathrm{X}<81$ & 87 & $58 \%$ \\
$\begin{array}{c}69,18 \leq \mathrm{X}< \\
80,15\end{array}$ & 40 & $26,7 \%$ & Rendah & $27 \leq \mathrm{X}<54$ & 0 & $0 \%$ \\
$\mathrm{X} \leq 69,18$ & 11 & $7,3 \%$ & Sangat & $\mathrm{X} \leq 27$ & 0 & $0 \%$ \\
\hline
\end{tabular}




\begin{tabular}{|c|c|c|c|c|c|}
\hline \multicolumn{6}{|c|}{ Rendah } \\
\hline Total & 150 & $100 \%$ & Total & 150 & $100 \%$ \\
\hline
\end{tabular}

Berdasarkan tabel diatas, dapat diketahui bahwa jika dilihat dari data hipotetik sebagian besar subjek berada pada kategori tinggi yaitu sebanyak 87 orang atau $58 \%$, kategori sangat tinggi sebanyak 87 orang atau 58\%, dan tidak ada atau $0 \%$ di dalam kategori rendah, sangat rendah. Jika dilihat dari data empirik sebanyak 92 orang atau $61,3 \%$ subjek memiliki kemampuan belajar berdasar regulasi diri dengan kategori tinggi. Ada 40 orang atau 26,7\% subjek yang berada pada kategori rendah, 11 orang atau 7,3\% subjek pada kategori sangat rendah, dan 7 orang atau 4,7\% subjek memiliki kemampuan belajar berdasar regulasi diri pada kategori sangat tinggi. Dalam mengkategorikan belajar berdasar regulasi diri dalam belajar penulis menggunakan data empirik.

\section{HASIL ANALISIS DATA}

\section{Uji Normalitas}

Uji normalitas bertujuan untuk mengetahui distribusi sebaran dari skor variabel yang digunakan. Uji normalitas dalam penelitian ini menggunakan Test of Normality Kolmogorov-Simirnov test dengan bantuan software SPSS 17.0 for Windows. Data dikatakan berdistribusi normal apabila nilai signifikansi $>0,05$. Adapun hasil uji normalitas untuk variabel belajar berdasar regulasi diri dan perilaku menyontek dapat dilihat pada Tabel 5 berikut :

Tabel 5.Hasil Uji Normalitas

\begin{tabular}{lr|r|r|r|r|r}
\hline & \multicolumn{3}{c}{ Kolmogorov-Smirnov $^{\mathrm{a}}$} & \multicolumn{4}{c}{ Shapiro-Wilk } \\
& Statistic & \multicolumn{1}{c}{ Df } & \multicolumn{1}{c}{ Sig. } & Statistic & \multicolumn{1}{c}{ df } & \multicolumn{1}{c}{ Sig. } \\
\hline $\begin{array}{l}\text { Perilaku } \\
\text { Menyontek }\end{array}$ & .066 & 150 & .200 & .992 & 150 & .546 \\
\hline Regulasi Diri & .065 & 150 & .200 & .994 & 150 & .784 \\
\hline
\end{tabular}

*. This is a lower bound of the true significance.

\section{a. Lilliefors Significance Correction}

Berasarkan hasil uji normalitas menggunakan uji Kolmogorov-smirnov Test dapat deketahui bahwa nilai Asymp.Sig (2-tailed) untuk variabel perilaku menyontek sebesar 0,200 , yaitu nilai $0,200>0,05$, sehingga dapat disimpulkan bahwa sebaran data pada variabel perilaku menyontek berdistribusi normal. Selanjutnya pada tabel 5 juga dapat diketahui bahwa nilai Asymp.Sig (2-tailed) untuk variabel belajar berdasar regulasi diri sebesar 0,200 yaitu nilai $0,200>0,05$, sehingga dapat disimpulkan bahwa sebaran data pada variabel belajar berdasar regulasi diri berdistribusi normal. 


\section{UJI LINIERITAS}

Uji linieritas dilakukan untuk menguji apakah hubungan antara variabel bebas dan variabel terikat mengikuti garis lurus (linear). Pengujian linieritas dilakukan dengan bantuan Software SPSS Versi 17 IBM for Windows menggunakan pengujian Test for Linierity. Data variabel dikatakan linier apabila dilai Sig. $<0,05$. Adapun hasil uji linieritas antara variabel belajar berdasar regulasi diri dan perilaku menyontek dapat dilihat pada Tabel 6 berikut :

\section{Tabel 6 Hasil Uji Linieritas}

\begin{tabular}{|c|c|c|c|c|c|c|c|}
\hline & & & $\begin{array}{l}\text { Jumlah } \\
\text { kuadrat }\end{array}$ & $\mathrm{df}$ & $\begin{array}{l}\text { Rata- } \\
\text { rata } \\
\text { kuadrat }\end{array}$ & $\mathrm{F}$ & Sig. \\
\hline \multirow{5}{*}{$\begin{array}{l}\text { Regulasi diri } \\
* \text { perilaku } \\
\text { menyontek }\end{array}$} & \multirow{3}{*}{$\begin{array}{l}\text { Antar } \\
\text { kelomp } \\
\text { ok }\end{array}$} & $\begin{array}{l}\text { (digabun } \\
\text { gkan) }\end{array}$ & 1988.607 & 25 & 79.544 & 1.650 & .039 \\
\hline & & $\begin{array}{l}\text { Linearita } \\
\mathrm{S}\end{array}$ & 553.847 & 1 & 553.847 & 11.492 & .001 \\
\hline & & $\begin{array}{l}\text { Deviasi } \\
\text { dari } \\
\text { linearitas }\end{array}$ & 1434.761 & 24 & 59.782 & 1.240 & .221 \\
\hline & \multicolumn{2}{|c|}{ Dalam kelompok } & 5976.166 & 124 & 48.195 & & \\
\hline & \multicolumn{2}{|l|}{ Total } & 7964.773 & 149 & & & \\
\hline
\end{tabular}
erdasark an hasil uji linieritas tersebut dapat diketahu i bahwa nilai $\mathrm{F}$ sebesar 11.492 dan Sig. sebesar 0,001, yaitu nilai 0,001<0,05, sehingga dapat disimpulkan bahwa variabel belajar berdasar regulasi diri dan perilaku menyontek mempunyai hubungan yang linear.

\section{UJI HIPOTESIS}

Berdasarkan penelitian ini uji hipotesis yang digunakan yaitu uji korelasi product moment dengan menggunakan Software SPSS Vers 17 IBM for Windows. Analisis yang digunakan yaitu apabilai nilai Sig. < 0,05 maka dapat disimpulkan terdapat hubungan antara variabel bebas dan terikat. Adapun hasil pegujian hipotesis dapat dilihat pada Tabel 7.

Tabel 7. Hasil Uji Korelasi Product Moment

\begin{tabular}{llr|r}
\hline & & Perilaku Menyontek & \multicolumn{1}{c}{$\begin{array}{c}\text { Belajar Berdasar } \\
\text { Regulasi Diri }\end{array}$} \\
\hline Perilaku & Korelasi Pearson & 1 & $-.264^{* *}$ \\
\cline { 2 - 4 } menyontek & Sig. (2-tailed) & 150 & .001 \\
\cline { 2 - 4 } & $\mathrm{N}$ & $-.264^{* *}$ & 150 \\
\hline Belajar & Korelasi Pearson & .001 & 1 \\
\cline { 2 - 4 } $\begin{array}{l}\text { berdasar } \\
\text { Regulasi Diri }\end{array}$ & Sig. (2-tailed) & 150 & 150 \\
\cline { 2 - 4 } & $\mathrm{N}$ & &
\end{tabular}

**. Korelasi Singnifikan pada tingkat 0.01 (2-tailed). 
Berdasarkan hasil pengujian hipotesis menggunakan uji korelasi product moment diperoleh nilai Sig. (2-tailed) sebesar 0,001, yaitu nilai 0,001<0,05, dengan nilai korelasi $r$ sebesar -0,264 termasuk dalam kategori sangat rendah, sehingga dapat disimpulkan bahwa hipotesis dalam penelitian ini diterima, yaitu terdapat hubungan negatif antara belajar berdasar regulasi diri dengan perilaku menyontek. Artinya semakin tinggi belajar berdasar regulasi regulasi diri maka semakin rendah tingkat perilaku menyontek pada mahasiswa. Begitu pula sebaliknya semakin rendah tingkat belajar berdasar regulasi diri maka semakin tinggi perilaku menyonteknya.

\section{DISKUSI}

Berdasarkan analisis ditemukan ada hubungan yang negatif antara belajar berdasar regulasi diri dengan perilaku menyontek mahasiswa sehingga hipotesis yang diajukan oleh penelitian ini diterima, yaitu terdapat hubungan antara belajar berdasar regulasi diri dengan perilaku menyontek. Artinya semakin tinggi belajar berdasar regulasi diri maka semakin rendah tingkat perilaku menyontek pada mahasiswa. Begitu pula sebaliknya semakin rendah tingkat belajar berdasar regulasi diri maka semakin tinggi perilaku menyontek pada mahasiswa. Besarnya hubungan tersebut dapat diketahui dengan melihat koefisien korelasi ( $\mathrm{r}$ ) yaitu sebesar $-0,264$ dan $\mathrm{p}=0,001(\mathrm{p}<0,05)$.

Menyontek diartikan sebagai menyalin, curang, mencoba melakukan sesuatu yang menguntungkan diri dengan segala cara. Menurut Hamdani (2015) menyontek adalah melakukan kegiatan yang bertujuan untuk mencari jawaban atas soal-soal ujian yang dilakukan dengan cara tertentu sehingga tidak diketahui oleh orang lain.

Fitriya dan Lukmawati (2016) menyatakan bahwa rendahnya belajar berdasar regulasi diri akan mampu menyebabkan seorang individu tidak mampu mengatur berbagai stimulus sehingga ketidakmampuan tersebut dapat menghambat individu menyelesaikan berbagai masalah akademik secara tepat dan maksimal. Dengan adanya kerjasama antara belajar berdasar regulasi diri dengan individu itu sendiri dapat membantu menghasilkan peningkatan yang baik terhadap proses belajar bagi seorang mahasiswa.

Setiap individu memiliki perbedaan dalam proses belajarnya. Salah satu perbedaan tersebut adalah kemampuan individu belajar berdasar regulasi diri. Individu yang memiliki kemampuan belajar berdasar regulasi diri yang baik, akan mampu belajar dengan kemampuanya sendiri. Salah satu faktor yang mempengaruhi belajar berdasar regulasi diri adalah efikasi diri. Purnamasari (2013) menyatakan bahwa terdapat aspek Efikasi Diri pada mahasiswa yang hendak melakukan tindak curang atau tidak dalam situasi ujian. Gagasan tersebut mencakup bagaimana seseorang berpikir mengenai aturan-aturan untuk membenarkan keputusan yang akan diambilnya. Semakin baik penalaran mahasiswa, maka semakin mudah untuk menghindari diri dari tindak kecurangan akademik.

Penelitian yang dilakukan Kushartanti (2009) menyebutkan bahwa perilaku menyontek sangat dipengaruhi oleh kepercayaan diri individu. Kepercayaan diri merupakan hal yang penting untuk dimiliki di dalam diri individu. Dengan memiliki rasa percaya diri maka kita akan mampu menentukan sikap yang akan kita ambil terhadap suatu permasalahan. Sejalan dengan penelitian yang dilakukan Bintoro dkk (2013) yang menyebutkan bahwa mahasiswa yang belum dapat melaksanakan belajar berdasar regulasi 
diri secara maksimal dan masih mudah terpengaruh dengan lingkungannya dikarenakan mahasiswa tidak memiliki rasa percaya diri dengan kemampuan yang dimiliki untuk mencapai tujuannya tanpa harus melakukan kecurangan akademik.

Shara (2015) menyatakan bahwa menyontek merupakan tindak kecurangan dalam tes melalui pemanfaatan informasi yang berasal dari luar secara tidak sah. Seseorang yang memiliki efikasi diri atau keyakinan dalam menentukan bagaimana seseorang merasa, berfikir, memotivasi diri sendiri dalam berperilaku. Seseorang yang mempunyai keyakinan akan selalu mencoba mencari jalan keluar untuk melakukan serangkaian tindakan dalam menyelesaikan suatu tugas dan permasalahan. Oleh karena itu, jika efikasi diri seseorang tersebut tinggi maka akan meminimalkan tindak perilaku menyontek.

Penelitian yang dilakukan Rachmah (2015) menunjukkan bahwa mahasiswa dengan peran yang banyak mampu membentuk belajar berdasar regulasi diri yang tepat sehingga individu dapat mencapai tujuan yang diharapkan dalam proses pembelajaran. Adanya belajar berdasar regulasi diri ini tidak terlepas dari motivasi berprestasi yang individu miliki.

Kemampuan belajar berdasar regulasi diri terdiri dari beberapa faktor. Seperti yang telah dijelaskan melalui beberapa penelitian diatas, terdapat faktor efikasi diri didalamnya. Individu dengan efikasi diri yang tinggi terbukti lebih memiliki kualitas yang baik dalam strategi belajar dan lebih memonitor hasil belajar mereka sendiri dibanding dengan individu dengan efikasi diri yang rendah. Begitu juga dengan kepercayaan diri, saat individu percaya akan kemampuan yang ada didalam dirinya, maka individu tersebut akan mampu memilih dan memilah hal apa yang akan diputuskan terhadap suatu masalah.

\section{KESIMPULAN}

Berdasarkan analisis data dapat disimpulkan bahwa terdapat hubungan negatif antara belajar berdasar regulasi diri terhadap perilaku menyontek. Hubungan negatif tersebut menunjukkan bahwa semakin tinggi perilaku menyontek, maka semakin rendah belajar berdasar regulasi dirinya. Begitu juga sebaliknya, semakin rendah perilaku menyontek, maka semakin tinggi belajar berdasar regulasi dirinya. Belajar berdasar regulasi diri memberi pengaruh sebanyak 20\% terhadap perilaku menyontek. Saran kepada mahasiswa diharapkan dapat lebih mengasah kemampuan belajar berdasar regulasi diri yang ada dalam dirinya. Strategi yang dapat dilakukan diantaranya mahasiswa bisa membuat skala prioritas dalam aktivitas sehari-hari, skala prioritas mengerjakan tugas perkuliahan, manajemen waktu dan tidak menunda-nunda mengerjakan tugas perkuliahan.Kemudian mahasiswa dapat menyesuaikan tempat belajar yang nyaman agar mampu memfokuskan pikiran pada saat belajar serta menyingkirkan hal-hal yang bias mengganggu konsentrasi belajar.

\section{DAFTAR PUSTAKA}

Albrecht, W.S, C. C. Albrecht, and C. O Albrecht. (2006). Fraud Examination. Second Edition, Thompson South Western, Canada.

Aji, Swanida Manik. (2013) Pengaruh Motivasi Berprestasi terhadap Prestasi Belajar 
Akuntansi siswa kelas X Akuntansi SMK N 1 Batang Tahun pelajaran 2012/2013, Skripsi, Fakultas Ekonomi Unnes, Semarang,

Alschuler, A. S., \& Blimling, G. S. (1995). Curbing epidemic cheating through systemic change . College Teaching, 43, 123-125.

Azwar, Saifuddin. (2014). Metode Penelitian. Yogyakarta: Pustaka Pelajar.

Bandura, A., Caprara, G. V., Barbaranelli, C., Pastorelli, C., \& Regalia, C. (2001). Sociocognitive self-regulatory mechanisms governing transgressive behavior. Journal of Personality and Social Psychology, 80, 125-135

Baird, J. S., Jr. (1980). Current trends in college cheating. Psychology in the Schools 17 (4): 515-22.

Baumesiter F Roy( 1996). Self-Regulation and the Executive Function: The Self as Controlling Agent.Chapter prepared for A. W. Kruglanski \& E.T. Higgins, Social psychology: Handbook of basic principles (Second edition). New York: Guilford.

Bintoro, Purwanto \& Noviyani. (2013). Hubungan Self Regulated Learning dengan Kecurangan Akademik pada Mahasiswa. Jurnal Psikologi. 2(1). Fakultas Ilmu Pendidikan, Universits Negeri Semarang.

Davis, S. F., Grover, C. A., Becker, A. H., \& McGregor, L. N. (1992). Academic dishonesty: Prevalence, determinants, techniques, and punishments. Teaching of Psychology, 19, $16-20$

Elias R. (2009). The impact of anti-intellectualism attitudes and academic self-efficacy in business students' perception of cheating. Journal of Business Ethics, 86, 199209.

Stevens, G., and F. Stevens. 1987. Ethical inclinations of tomorrow's managers revisited: How and why students cheat. Journal of Education for Business 63 (1): 24-29.

Pintrich, P. (2000). Multiple goals, multiple pathways: The role of goal orientation in learning and achievement. Journal of Educational Psychology, 92, 544-555

Kristiyani. K. (2016). Self Regulated Learning, Yogyakarta: Sanata Dharma Univerity Press.

Kushartanti, A. (2009). Perilaku Menyontek ditinjau dari Kepercayaan Diri. Fakultas Psikologi, Universitas Muhammadiyah: Surakarta.

Loppies, A.M. (2014). Hubungan antara Self Regulated Learning dengan Kecurangan Akademik pada Mahasiswa Fakultas Teknik Informatika UKSW. Skripsi, Fakultas Psikologi Universitas Kristen Satya Wacana: Salatiga.

McCabe, D., \& Trevino, L. (1997). Individual and contextual influences on academic dishonesty: A multi campus investigation. Research in higher education, 38, 379-396.

Murdock T.B., Hale N.M., \& Weber M.J. (2001). Predictors of cheating among early adolescents: Academic and social motivations.Contemporary Educational Psychology, 26, 96-115.

Sims, R. L. 1993. The relationship between academic dishonesty and unethical business practices. Journal of Education for Business 68(4): 207-13

Shara, S. (2015). Hubungan Self Efficacy dan Perilaki Menyontek pada Mahasiswa Universitas X. Jurnal Psikologi. 9(1). Hal. 42-48

Sugiyono. (2016). Metode Penelitian Pendekatan Kuantitatif, Kualitatif. Bandung: Alfabeta Santoso, S. (2010). Mastering SPSS 18. Jakarta: PT Elex Media Komputindo. 
Zimmerman, B. J. (2005). Attaining self-regulation: A social cognitive perspective. In M. Boekaerts, P. R. Pintrich, \& M. Zeidner (Eds.). Handbook of self-regulation (pp. 1339). (2nd ed.). San Diego, CA: Academic Press. 